Check for updates

Cite this: Mater. Adv., 2020, 1,2124

Received 10th July 2020, Accepted 19th August 2020

DOI: $10.1039 / \mathrm{d} 0 \mathrm{ma} 00494 \mathrm{~d}$

rsc.li/materials-advances

\title{
Bimetallic tungstate nanoparticle-decorated-lignin electrodes for flexible supercapacitors $\dagger$
}

\author{
Swarn Jha, ${ }^{a}$ Siddhi Mehta, ${ }^{\mathrm{b}}$ Eugene Chen, ${ }^{\mathrm{b}}$ Selvasundarasekar Sam Sankar, \\ Subrata Kundu (iD ${ }^{c}$ and Hong Liang (iD *ab
}

\begin{abstract}
Bimetallic tungstates $\left(\mathrm{M}_{2} \mathrm{M}_{1} \mathrm{WO}_{4} ; \mathrm{M}=\right.$ transition metal) are promising candidates for electrochemical energy applications. However, the effects of the secondary metal $\left(M_{2}\right)$ on the pseudocapacitance behavior of bimetallic tungstates have not been well understood. We report, for the first time, the effect of a secondary metal $(\mathrm{Ni})$ on the pseudocapacitance of a bimetallic tungstate $\left(\mathrm{NiWO}_{4} / \mathrm{CoWO}_{4}\right.$ composite called as $\mathrm{NiCoWO}_{4}$ hereafter) when used in a quasi-solid-state supercapacitor. Nanoparticles of $\mathrm{NiCOWO}_{4}$ and $\mathrm{CoWO}_{4}$ were prepared using a wet chemical synthesis technique and characterized using SEM, XPS, XRD, EDX, and XPS. Lignin/NiCoWO $4 / / A C$ and lignin/CoWO $/ /$ AC supercapacitors were electrochemically tested using Electrochemical Impedance Spectroscopy, cyclic charge-discharge, and cyclic voltammetry. After 2000 charge-discharge cycles, the bimetallic tungstate $\left(\mathrm{NiCOWO}_{4}\right)$ functionalized lignin supercapacitor shows a specific capacitance $\left(862.26 \mathrm{mF} \mathrm{cm} \mathrm{cm}^{-2}, 96.12 \%\right.$ retention) that is 141 times that of the monometallic tungstate $\left(\mathrm{COWO}_{4}\right)$ functionalized lignin supercapacitor. The lignin/NiCoWO ${ }_{4}$ supercapacitor has very high power and energy densities of $854.76 \mathrm{~kW} \mathrm{~kg}^{-1}$ and $5.75 \mathrm{~W} \mathrm{~h} \mathrm{~kg}^{-1}$, respectively, due to a synergistic effect of bimetallic tungstate nanoparticles encapsulated in lignin. The supercapacitor design explored detailed aspects of composite electrode constituent optimization, and the effects of discharge time, lignin carbonization, and cathode material on the supercapacitor performance. For an optimal mass ratio of lignin: $\mathrm{NiCoWO}_{4}$ : PVDF $(15: 75: 10)$, the retention was $100 \%$ even after 2000 cycles. In addition to the cathode material's permittivity and surface area, the supercapacitor's electrochemical performance heavily depended on the dominant charge storage regime: an electric double-layered capacitor or pseudocapacitor dominant regime. This work provides new knowledge to design bimetallic tungstate based high-performance bioelectronics for advanced green technology.
\end{abstract}

\section{Introduction}

To meet the rising demands of energy storage and sustainability, there are impending needs to discover new high-performance eco-friendly materials. ${ }^{1-6}$ Electrochemical energy storage systems, like batteries and supercapacitors, are considered to be excellent options. $^{7-13}$ Supercapacitors exhibit high performance using bioderived materials and nanomaterials. ${ }^{14-16}$ Recently, oxide/hydroxide

' J. Mike Walker '66 Department of Mechanical Engineering, Texas A\&M University, 202 Spence Street, College Station, TX 77843-3123, USA.

E-mail: hliang@tamu.edu; Fax: +979-845-3081; Tel: +979 8622623

${ }^{b}$ Department of Materials Science \& Engineering, Texas A\&M University, College Station, Texas 77843, USA

${ }^{c}$ Electrochemical Process Engineering (EPE) Division, CSIR-Central Electrochemical Research Institute (CECRI), Karaikudi, Tamilnadu-630003, India

$\dagger$ Electronic supplementary information (ESI) available: Synthesis of nanoparticles; XPS spectra of $\mathrm{CoWO}_{4}$ nanoparticles; optical microscopy images of electrodes; interferometer images of electrodes; table summary for electrochemical experiments; table for performance comparison with literature reports. See DOI: $10.1039 / \mathrm{d} 0 \mathrm{ma} 00494 \mathrm{~d}$ based transition metals have garnered extensive attention toward electrochemical applications. ${ }^{17-20}$ But, these materials have poor cyclic stability, electroconductivity, and rapid capacitance degradation. The corrosion resistance and exceptional physiochemical properties of tungsten, combined with the nontoxic and stable multi-functional properties of the metal, make tungsten compounds an attractive choice. ${ }^{21}$ Metal tungstates find applications in various fields, for instance, in optical fibers, photoluminescence, and microwave applications, which make them an integral part of the metal oxide family. ${ }^{22}$ Metal tungstates with the empirical formula $\mathrm{MWO}_{4}(\mathrm{M}=\mathrm{Ni}, \mathrm{Cu}, \mathrm{Co}$, $\mathrm{Mn})$ are particularly versatile and have found uses in Li-ion batteries and dielectric ceramics as well. ${ }^{23} \mathrm{CuWO}_{4}$ crystals are frequently used for a variety of applications such as photoelectrocatalytic water oxidization or magnetism. ${ }^{24}$ Precision in the bandgap energy of $\mathrm{MWO}_{4}$ is highly crucial for several applications like the detectors used in the Large Hadron Collider at CERN and Raman lasers which are safe for eyes. ${ }^{25}$ $\mathrm{CuWO}_{4}$ nanoparticles (NPs) were synthesized using a sonochemical 
method which showed that the copper crystals are a favorable material for photocatalytic applications. ${ }^{26}$ Feng et al. in 2017 studied the electrochemical behaviors of $\mathrm{CoWO}_{4}, \mathrm{NiWO}_{4}$, and $\mathrm{CoWO}_{4} @ \mathrm{NiWO}_{4} \mathrm{-A}$ and suggested that these metal tungstate compounds could be considered as good electrode materials for energy storage applications. ${ }^{27}$

In the design of metal tungstate based electrodes, several aspects are crucially important for consideration: chemical structure, conductivity, charge transport mechanism, nature of transition metals, size, and the temperature range of operation. Tungstates of transition metals such as $\mathrm{Co}, \mathrm{Ni}, \mathrm{Cu}$, and $\mathrm{Zn}$ of the form $\mathrm{MWO}_{4}\left(\mathrm{M}=\right.$ metal), except for $\mathrm{CuWO}_{4}$, are found to possess a monoclinic wolframite-type structure. Wolframite structures (with $\mathrm{Zn}$ and $\mathrm{Mg}$ ) have shown promising electrode material for dye-sensitized solar cells, while the scheelite structure (with $\mathrm{Ca}$ and $\mathrm{Sr}$ ) operated with a lower electron transfer rate. ${ }^{28} \mathrm{Hoang}$ et al., in 2018, carried out a hybrid density-functional analysis of the electronic structure and established that a polaron was formed through the underlying mechanism for the existence of p-type semiconductivity in $\mathrm{CoWO}_{4}{ }^{29}$ The conductance of $\mathrm{CuWO}_{4}$ is attributed to the hopping of small polarons. In 2017, Hoang et al. conducted a first-principles study of iron tungstate $\left(\mathrm{FeWO}_{4}\right)$ and manganese tungstate $\left(\mathrm{MnWO}_{4}\right)$ to attain a detailed understanding of their properties such as lattice parameters, static dielectric constants, and band gaps. ${ }^{30}$ In their study, it was found that highly mobile polarons with low energy are formed near the band edges due to localized transition-metal d states. As a result, these materials exhibit high p-type conductivity. Also, $\mathrm{WO}_{4}$ type transition metal tungstates (TMT) are associated with magnetic ordering due to which the conduction electrons have modified energy spectra. This leads to a higher electrical resistivity in TMT than metals. ${ }^{31}$ Montini et al., in 2010, found that the nature of transition metals determines the photocatalytic and optical properties in $\mathrm{MWO}_{4}$ type compounds. Despite having a huge bandgap, $\mathrm{ZnWO}_{4}$ showed the highest photocatalytic activity possibly due to the hybridization of partially empty $3 \mathrm{~d}$ orbitals with $\mathrm{W} 5 \mathrm{~d}$ orbitals that is in the lower level of the conduction band. $^{32}$ Perales $e t$ al., in 2008, determined the bandgap energy $(5.26 \mathrm{eV})$ in some tungstates $\left(\mathrm{MWO}_{4}\right)$ and reasoned that the hybridization of $\mathrm{p}, \mathrm{d}$, and $\mathrm{f}$ electronic states of $\mathrm{M}^{2+}$ with the $\mathrm{O} 2 \mathrm{p}$ and $\mathrm{W} 5 \mathrm{p}$ orbitals lowered the bandgap energy. ${ }^{25}$ The size of the cation in the $\mathrm{MWO}_{4}$ type determines the dielectric permittivity. ${ }^{33}$ Nagirnyi et al. found that excitons were created as a result of transition to the $\mathrm{W} 5 \mathrm{~d}$ orbital in $\mathrm{CdWO}_{4}$ at 6-300 K and 3.5-3.0 eV. At energies 1-2 eV higher than the conduction band energy, holes and free electrons were created due to the cation state transition. ${ }^{34}$ The temperature range of application plays a fundamental role in the type of transition metal selection for electrodes. Below $455 \mathrm{~K}$, the hopping mechanism involving small polarons leads to extrinsic type conduction behavior in $\mathrm{CoWO}_{4}$, while, above $455 \mathrm{~K}$, an intrinsic behavior was observed due to large polaron hopping. ${ }^{31}$ The A.C. and D.C. electrical conductance of manganese tungstate $\left(\mathrm{MnWO}_{4}\right)$ was measured at the given temperatures ranging from $300-1250 \mathrm{~K}$, and it was established that $\mathrm{MnWO}_{4}$ showed a p-type behavior. ${ }^{35} \mathrm{NiWO}_{4}$ is a p-type compound under $660 \mathrm{~K}$, n-type between $660 \mathrm{~K}$ and $950 \mathrm{~K}$ and p-type above $950 \mathrm{~K}$. The dielectric constant of the observed $\mathrm{NiWO}_{4}$ decreased with temperature ranging from $300 \mathrm{~K}$ to $350 \mathrm{~K}$. It increased slowly with temperature until about $700 \mathrm{~K}$ and increased rapidly after that. ${ }^{36}$

Co and Ni are well complemented by each other, and Co provides good rate capability and cyclic stability while Ni shows high specific capacitance (SPC). A hybrid tungstate of Ni-Co also shows better conductivity due to the incorporation of $\mathrm{W}$ atoms. Rajpurohit et al., in 2019, prepared bimetallic Co-Ni tungstate NPs and a composite with P-S co-doped graphene by hydrothermal synthesis and used as an electrode for the supercapacitor. ${ }^{23}$ Nickel-based materials possess high theoretical specific capacity but their low rate capability limits their use in supercapacitor applications. In contrast, cobalt-based materials possess good rate capability but possess a low specific capacity. Hence, a combination of these materials would possess the desired characteristics for use as positive electrodes in hybrid supercapacitors. In various studies of $\mathrm{NiWO}_{4}$ and $\mathrm{CoWO}_{4}$ electrodes, high SPC and retention were obtained. In one study, nanocomposites of $\mathrm{NiWO}_{4} / \mathrm{CoWO}_{4}$ were synthesized which showed high capacitive performance. ${ }^{21} \mathrm{Co}^{2+}$ was incorporated into the $\mathrm{NiWO}_{4}$ lattice via a chemical co-precipitation method to manufacture monoclinic wolframite nanosheets of $\mathrm{Ni}_{1-\mathrm{x}} \mathrm{Co}_{x} \mathrm{WO}_{4}$. In comparison to $\mathrm{NiWO}_{4}$, the surface area and the electrical conductivity of $\mathrm{Ni}_{1-x} \mathrm{Co}_{x} \mathrm{WO}_{4}$ increased considerably. However, the $\mathrm{NiWO}_{4}$ electrode exhibited better cycle stability. Based on the results obtained so far, it is predicted that the performance can be boosted by mixed transition metal oxides (MTMOs) ${ }^{21,37}$ Wang et al., in 2016, used this reasoning to synthesize a mesoporous $\mathrm{NiWO}_{4} @ \mathrm{CoWO}_{4}$ nanocomposite with different $\mathrm{Co} / \mathrm{Ni}$ molar ratios using a chemical co-precipitation method. It was determined that the supercapacitor fabricated by using this composite exhibited a high energy storage density of $30.1 \mathrm{~W} \mathrm{~h} \mathrm{~kg}^{-1}$ and a higher power density of $200 \mathrm{~W} \mathrm{~kg}{ }^{-1} \cdot{ }^{38} \mathrm{~A}$ recent review focused on the advancement of mixed transition metal oxides and their hybridization with graphene sheets makes active materials for electrodes. ${ }^{39}$ Critical factors affecting the electrochemical performance, as well as the low electroconductivity and other limitations of these oxides were highlighted. Graphene sheets hybridized with mixed transition metal oxides resulted in a high specific surface area and good electroconductivity. The mixed transition metal oxides (MTMOs), in comparison to transition metal oxides (TMOs), exhibit better electrochemical properties. This can be attributed to the combined effect of multiple oxidation states in transition metal oxides which gives an ideal pseudocapacitance due to the diverse redox reactions. The number of electroactive sites and electrolyte ion accessibility play a major role in the performance of the electrochemical system along with the porosity, specific surface area, and morphology of the active material. ${ }^{40}$ The combined effect of two different TMOs increases the number of electroactive sites as well as the potential window. In addition to their low-cost, abundant availability and eco-friendliness make MTMOs excellent candidates for active electrode materials. Despite the superior electrochemical performance, MTMOs have several limitations as well. These include poor cyclic stability, rate capability and intense 
volume expansion during the reversible charge-discharge process. To improve this, MTMOs are customized into nanostructures. ${ }^{41}$

Over the years there have been significant advancements in the synthesis of metal tungstates and tungsten oxides. $\mathrm{CuWO}_{4}$ was synthesized using the chemical precipitation method and the parameters were optimized using a Taguchi robust design. The method did not use templates or catalysts which made it very simple and fast in comparison to other methods. ${ }^{42}$ Zawawi et al., in 2013, executed the synthesis of three separate metal tungstate phases using the sucrose templated method. The phase achieved by each metal tungstate, and the relationship between bivalent cation size and the structural properties were dependent on the divalent cation used. ${ }^{43}$ Priya et al., in 2011, used a co-precipitation method to synthesize $\mathrm{CdWO}_{4}$ crystals. Increasing temperature and frequency were found to have a positive correlation on the electrical conductivity, thus, demonstrating the semiconducting nature of the material. ${ }^{22}$ One notable and simple process is the microwave synthesis of a nano-crystalline metal tungstate, investigated through the use of radiation from a cyclic microwave and the organic compound propylene glycol. ${ }^{44}$ Parhi et al., in 2008, used a microwave to synthesize metal tungstates using a solid-state metathetic (SSM) method. ${ }^{45}$ It was found that reaction time, $\mathrm{pH}$, and temperature strongly influenced the synthesis of the single-crystal nanowire of silver tungstates using hydrothermal re-crystallization. ${ }^{46}$ Talebi et al., in 2016, synthesized the $\mathrm{NiWO}_{4} \mathrm{NP}$ using the ultrasound method and used it to study the photocatalytic degradation of methyl orange. ${ }^{47}$ Shinde et al., in 2020, explained the $\mathrm{pH}$ - and potential-dependent behavior of tungsten in an aqueous medium, as well as the tungsten oxide crystal structures. ${ }^{48}$ Various tungstate trioxide-based materials have been synthesized and tested extensively. However, tungstate trioxide has a low energy density and surface area. Therefore, more research is required to enhance their performance as active electrode materials. ${ }^{48}$ Wet chemical synthesis is one of the widely used techniques for the synthesis of NPs, which commonly deals with the chemical reaction occurring in its solution phase. Of the many methods available for the synthesis of NPs such as solvothermal and template synthesis, oriented attachment, self-assembly, etc., the wet chemical synthesis method offers a high degree of material reproducibility and controllability. The uniformity of the produced compounds is also ensured by this route. ${ }^{49,50}$ Recently, lignin-based carbon materials have shown promising activity in supercapacitors. ${ }^{51,52}$ However, challenges exist in terms of achieving high power and energy densities, cyclic stability, and long term cyclic stability for application purposes. Besides, the state-of-art use of lignin emphasizes the use of hazardous processes such as using polyacrylonitrile (PAN) based fibers, or expensive and unsafe techniques like electrospinning. As such, there is a need to design and develop a new lignin-based material and process that is efficient, safe, and reliable for use.

The objectives of this research are: (1) to understand the effect of the secondary metal (Ni) in the bimetallic tungstate composite $\left(\mathrm{NiCoWO}_{4}\right)$ in affecting its electrochemical behavior, (2) to assess and optimize the performance, and layout the design strategy for a synergistic design of the bimetallic tungstate NP functionalized lignin-based supercapacitors based on green chemistry principles. To attain these objectives, a bimetallic tungstate NP functionalized alkali lignin (lignin/ $\mathrm{NiCoWO}_{4}$ ) based supercapacitor is designed. It is then compared for electrochemical performance with a metallic tungstate nanoparticle functionalized alkali lignin (lignin/CoWO ${ }_{4}$ ) based supercapacitor. The $\mathrm{NiCoWO}_{4}$ and $\mathrm{CoWO}_{4} \mathrm{NP}$ were prepared by using a wet chemical synthesis technique. NP characterization was done using XRD, XPS, EDX, and SEM. A supercapacitor study was done by using the electrochemical tests mentioned earlier. Effects of the secondary metal (Ni) in the bimetallic tungstate, discharge time, carbonized alkali lignin, and the cathode material were investigated. The design strategy explored in detail the aspects of composite electrode constituent optimization, and the effects of discharge time, lignin carbonization, and cathode material on the super capacitance performance.

\section{Experimental}

\subsection{Synthesis of $\mathrm{CoWO}_{4}$}

For this synthesis procedure, a simple wet chemical route was opted (Fig. S1a, ESI $\dagger$ ). $0.05 \mathrm{M}$ of cobalt acetate salt was added to distilled water $(50 \mathrm{ml})$ and stirred for $15 \mathrm{~min}$; this solution was denoted as solution A. Likewise, $0.1 \mathrm{M}$ of $\mathrm{Na}_{2} \mathrm{WO}_{4}$ salt is mixed with $100 \mathrm{ml}$ of DI water, which was then stirred for $30 \mathrm{~min}$ which was labeled as solution B. After that, solution A was added dropwise to solution B, followed by stirring it for $6 \mathrm{~h}$. A pink colored precipitate was formed which was centrifuged and dried.

\subsection{Synthesis of Ni-CoWO}

The mixture of $\mathrm{Ni}$ and Co bimetallic tungstates was prepared via a wet chemical approach (Fig. S1b, ESI $\dagger$ ). Then, $0.9 \mathrm{~g}$ of nickel acetate was mixed with $50 \mathrm{ml}$ of water (distilled) and the solution was stirred for 15 min until the homogeneity was observed. This solution was denoted as Solution A. $0.3 \mathrm{~g}$ of cobalt acetate was added to $50 \mathrm{ml}$ of DI water in a beaker and stirred for $15 \mathrm{~min}$. This solution was denoted as solution B. Likewise, 0.1 $\mathrm{M} \mathrm{Na}_{2} \mathrm{WO}_{4}$ was added to DI water $(100 \mathrm{ml})$ and then stirred for $30 \mathrm{~min}$. This was labeled as solution $\mathrm{C}$. Finally, solutions A and B were mixed dropwise into solution C simultaneously. The resultant solution was stirred for $6 \mathrm{~h}$ under magnetically stirred conditions. After that, the solution was centrifuged and dried. The final product was collected and annealed at $600{ }^{\circ} \mathrm{C}$ for $2 \mathrm{~h}$ with a temperature ramping rate of $5{ }^{\circ} \mathrm{C} \min ^{-1}$. The end product was denoted as $\mathrm{Ni}-\mathrm{CoWO}_{4}$.

\subsection{Fabrication of the lignin/Ni-CoWO ${ }_{4}$ and $\mathrm{CoWO}_{4}$ composite electrodes}

To study the novel NP, three ratios of varying wt\% were synthesized and analyzed via electrochemical testing. The ratios were prepared in the form $\mathrm{Lig}$ : $\mathrm{Ni}-\mathrm{CoWO}_{4}$ : PVDF. The first sample was prepared in the ratio of $80: 10: 10.0 .015 \mathrm{~g}$ of novel Ni-CoWO NPs were added to $0.12 \mathrm{~g}$ alkaline lignin (TCI Chemicals). A slurry of the obtained compound was made by using polyvinylidene 
difluoride (PVDF) as the binder and $3 \mathrm{ml}$ of NMP ( $N$-methyl-2pyrrolidone) as the solvent, both obtained from Sigma Aldrich. An aluminum foil of diameter $40 \mathrm{~mm}, 0.98 \mathrm{~mm}$ thick, and with adjacent strips of $10 \mathrm{~mm} \times 30 \mathrm{~mm}$ was used as the substrate. The slurry obtained earlier was coated on the $\mathrm{Al}$ substrate. The coated substrate was thermally treated at $70{ }^{\circ} \mathrm{C}$ in a vacuum environment of $-21 \mathrm{Hg}$ vacuum pressure. Similarly, the other two samples of the ratios $75: 15: 10$ and $15: 75: 10$ were made and studied to arrive at the optimal performance. The same method was implemented to synthesize the $\mathrm{CoWO}_{4}$ electrode of the ratio $80: 10: 10$ and the $\mathrm{NiWO}_{4}$ electrode of ratio $10: 80: 10 .^{52}$ Regarding the fabrication of the electrolyte, the $\mathrm{PVA} / \mathrm{H}_{3} \mathrm{PO}_{4}$ electrolyte gel was prepared in the same manner as explained in our recently published work. ${ }^{52,53}$ For carbonized lignin, a carbonization procedure was followed: alkali lignin was heated at $300-400{ }^{\circ} \mathrm{C}$ in an argon atmosphere for 24 hours. The remaining fabrication process was the same as for the alkali lignin-based supercapacitor.

\subsection{Assembly of the asymmetric supercapacitors}

Two supercapacitor assemblies with different negative electrodes were prepared as shown in Fig. 1. The negative electrodes were Al foils coated with activated carbon (AC) and a graphene sheet. Porous commercial paper was used as a separator in the supercapacitor assembly. The paper was completely immersed in the $\mathrm{PVA} / \mathrm{H}_{3} \mathrm{PO}_{4}$ electrolyte gel. The separator was then placed on the lignin-based composite electrode. The negative electrode was placed over the separator, effectively sandwiching the separator between the two electrodes to form the asymmetric supercapacitor assembly. The schematic is shown in Fig. 1.

\subsection{Characterizations}

XPS was studied using a Theta Probe AR-XPS system (Thermo Fisher Scientific, UK). For the XRD evaluation, a Bruker X-ray diffractometer was used. A sweeping rate of $5^{\circ} \min ^{-1}$ (2 $\theta$ range $\left.10-90^{\circ}\right)$ and $\lambda=0.154 \mathrm{~nm}\left(\mathrm{Cu} \mathrm{K}{ }_{\alpha}\right.$ radiation) was implemented. The Hitachi model $\mathrm{S}-3000 \mathrm{H}$ with a $30 \times$ to $300 \mathrm{k} \times$ magnification and an accelerating voltage of $\sim 0.3$ to $30 \mathrm{kV}$ was used for the EDS as well as SEM evaluation. The Olympus Leco PMG3 optical microscope (OM) at the Texas A\&M Materials Science Engineering Facility was used to obtain high contrast images. The interferometer model was a Zygo NewView 600 type (Zygo Corporation, CT). All electrochemical characterizations were performed using a Gamry version 6.33 potentiostat (Gamry Instruments, USA). EIS was carried out in the frequency range of $10^{6}-0.1 \mathrm{~Hz}$, and AC of $1 \mathrm{~V}$.

\section{Results and discussion}

\subsection{X-ray diffraction (XRD) pattern of nanoparticles}

To understand the nature exhibited by the materials, XRD studies were carried out. XRD studies reveal that $\mathrm{CoWO}_{4}$ is semi-crystalline in nature. There are some sharp peaks observed and these peaks correspond with the JCPDS number 00-015-0867 which reveals the formation of $\mathrm{CoWO}_{4}$. The distinct peak observed at the position of $35.7^{\circ}$ corresponds to the oxide of tungsten. The corresponding XRD spectrum is shown in Fig. 2(a).

The synthesized Ni-CoWO ${ }_{4}$ powder was subjected to X-ray diffraction studies (XRD). The subsequent XRD spectrum is shown in Fig. 2(b). The sharp peak reveals that the formed materials are crystalline. This pattern exactly matches the JCPDS reference number of 00-015-0867 and 00-015-0755 which corresponds to a mixture of cobalt and nickel tungstates, respectively. Other distinct peaks of $17.09,27.88$, and $32.73^{\circ}$ correspond to tungsten oxides $\left(\mathrm{W}_{x} \mathrm{O}_{y}\right)$ which matched with the reference number of 00-005-0392.

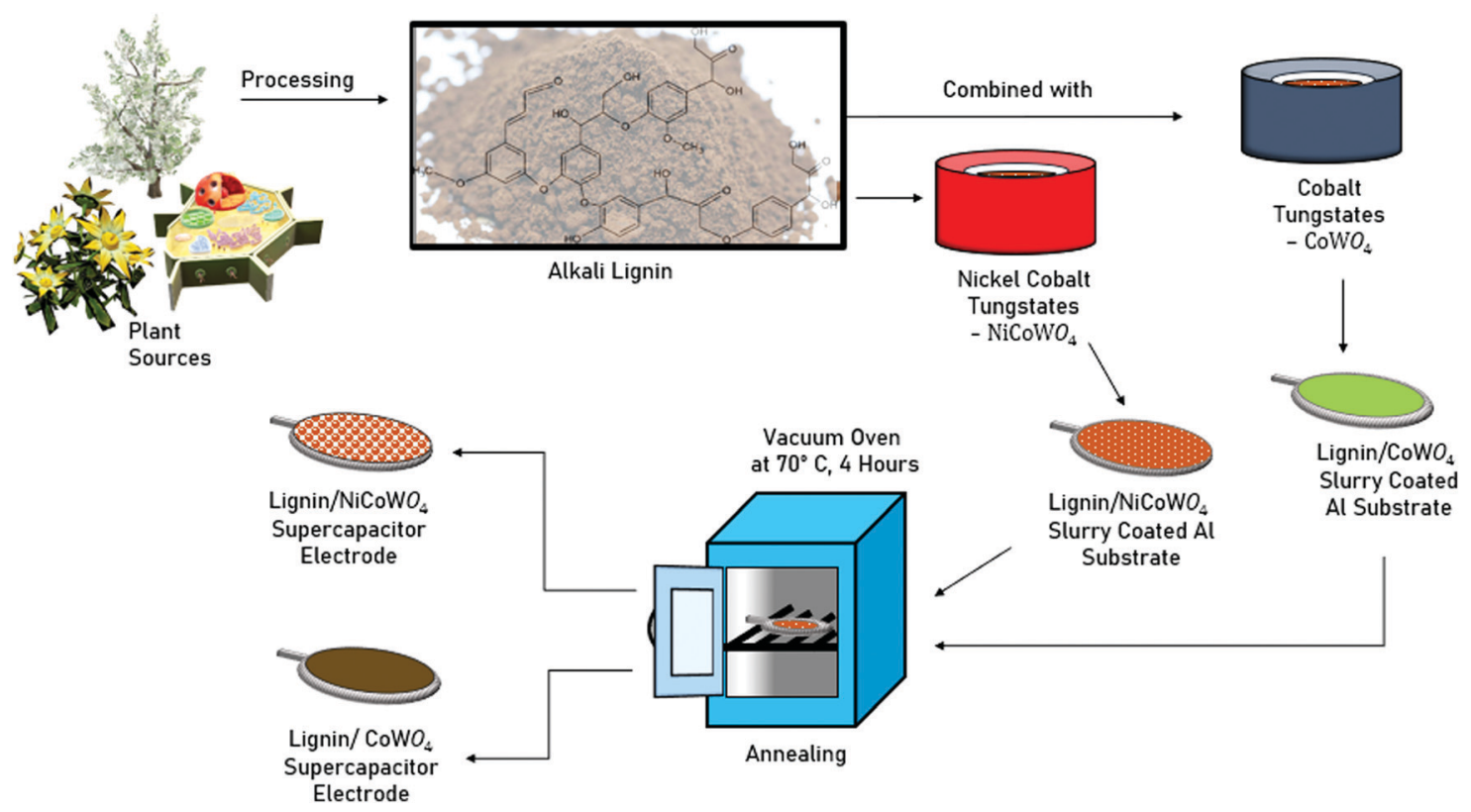

Fig. 1 Schematic for the fabrication of the composite electrodes. 

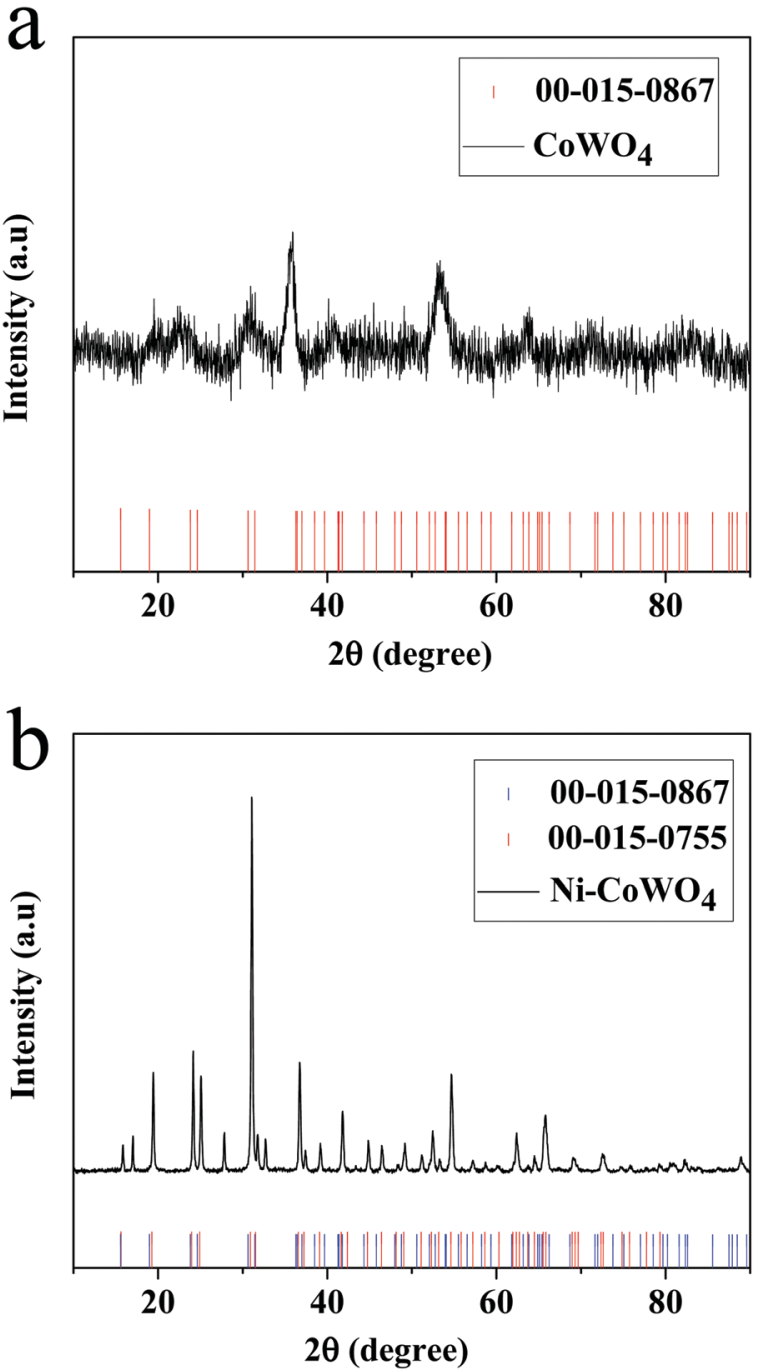

Fig. 2 XRD plots for the composite electrodes: (a) $\mathrm{CoWO}_{4}$, and (b) $\mathrm{Ni}-\mathrm{COWO}_{4}$

\subsection{Scanning electron microscopy (SEM) images of nanoparticles}

To know the morphological aspects, scanning electron microscopy (SEM) analysis was performed and the subsequent images are displayed in Fig. 3(a-d).

The low and high magnification images of $\mathrm{CoWO}_{4}$ (Fig. 3(a and b)) show a disordered plate-like morphology. In the same way, the low and high magnification images of $\mathrm{Ni}-\mathrm{CoWO}_{4}$ can also be seen in Fig. 3(c and d), respectively. In both cases, the observed materials are uniformly distributed all over the surface.

\subsection{Energy-dispersive X-ray (EDS) spectroscopy analysis of nanoparticles}

To confirm the elemental composition, EDS was carried out. The corresponding plots are shown in Fig. 4(a and b). The observed elements like cobalt, tungsten, and oxygen in $\mathrm{CoWO}_{4}$ have been shown in Fig. 4a. The presence of elements in $\mathrm{NiCoWO}_{4}$ such as nickel, cobalt, tungsten, and oxygen has
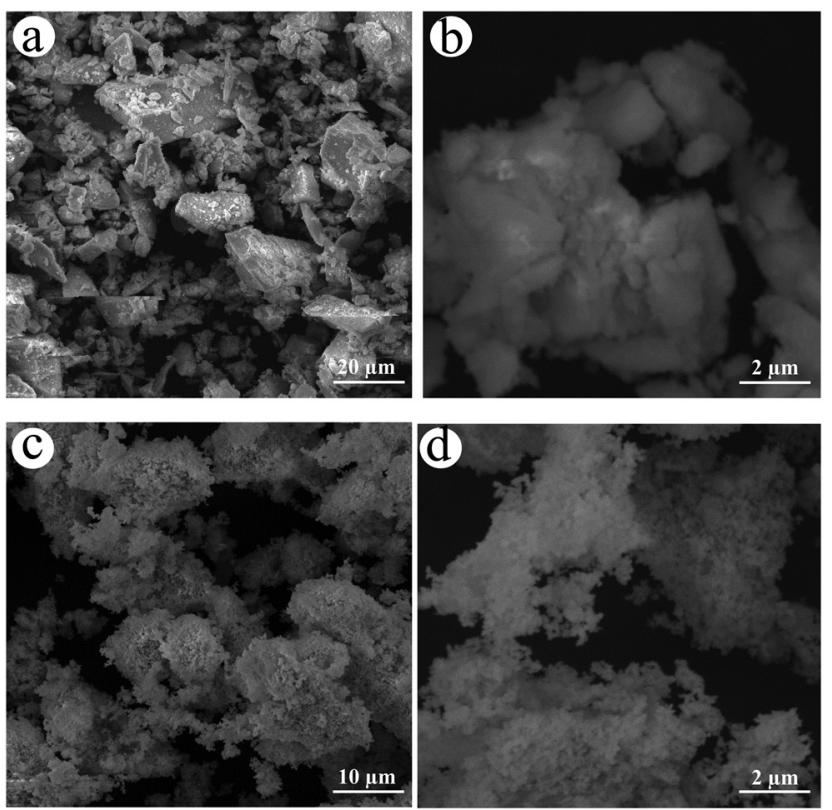

Fig. $3 \mathrm{SEM}$ images for (a) $\mathrm{CoWO}_{4}$ (low magnification), (b) $\mathrm{CoWO}_{4}$ (high magnification), (c) $\mathrm{Ni}-\mathrm{CoWO}_{4}$ (low magnification), and (d) $\mathrm{Ni}-\mathrm{CoWO}_{4}$ (high magnification).

been confirmed; the corresponding EDS spectrum is shown in Fig. $4 \mathrm{~b}$.

\subsection{High-resolution transmission electron microscopic (HR-TEM) analysis of nanoparticles}

To provide a deeper insight into the morphological analysis, low and high magnified HR-TEM images have been taken as shown in Fig. S2(a-d) (ESI $\dagger$ ), respectively. Herein, the abovementioned morphology of the nanoparticle has been confirmed once again. For the uniform distribution of elemental confirmation, high angle annular dark-field (HAADF) imaging and color mapping have been performed and the corresponding results are given in Fig. S3(a-f) (ESI $\dagger)$. While Fig. S3a is a HAADF image, S3b (ESI $\dagger$ ) is a mixed elemental distribution image, and the expected elements such as cobalt, nickel, tungsten, and oxygen are shown in Fig. S3(c-f) (ESI $\dagger$ ) respectively. The mapping results reveal that the expected elements are uniformly distributed all over the catalyst surface.

\subsection{X-ray photoelectron spectroscopy (XPS) of nanoparticles}

For identifying the nature of the elements, X-ray photoelectron spectroscopy (XPS) was carried out. Fig. 5a shows the highresolution XPS spectrum of Ni 2p. Herein, the binding energy values are observed at 873.3, 855.5 eV and 879.7, 861.54 eV corresponding to $\mathrm{Ni} 2 \mathrm{p}_{1 / 2}$, and $\mathrm{Ni} 2 \mathrm{p}_{3 / 2}$ and the corresponding satellite peaks respectively. Similarly, Fig. 5b shows the highresolution spectrum of Co $2 \mathrm{p}$ showing the binding energy values of $796.74,780.86 \mathrm{eV}$, and $802.46,785.64 \mathrm{eV}$, corresponding to $\mathrm{Ni} 2 \mathrm{p}_{1 / 2}$ and $\mathrm{Ni} 2 \mathrm{p}_{3 / 2}$ and the corresponding satellite peaks, respectively. Both nickel and cobalt possess an oxidation state of +2 . Fig. $5 \mathrm{c}$ shows the high-resolution spectrum of $\mathrm{W} 4 \mathrm{f}$ 
a

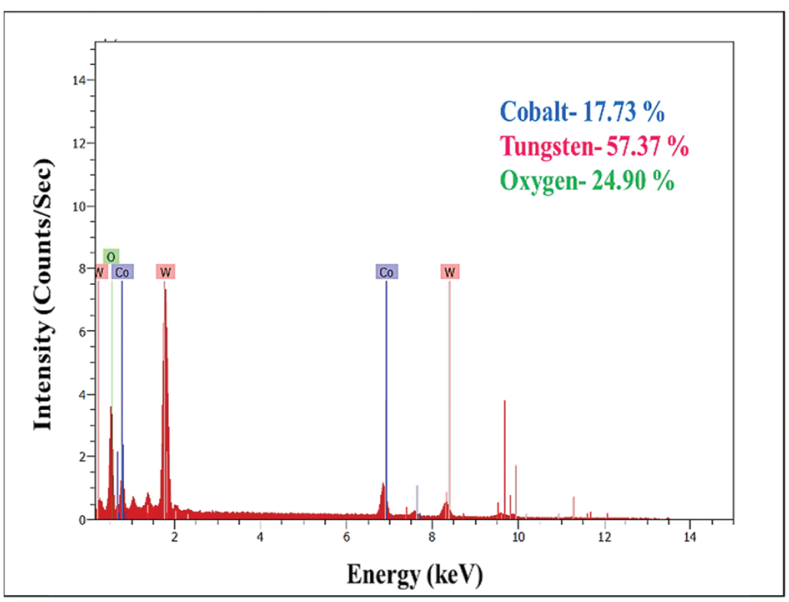

b

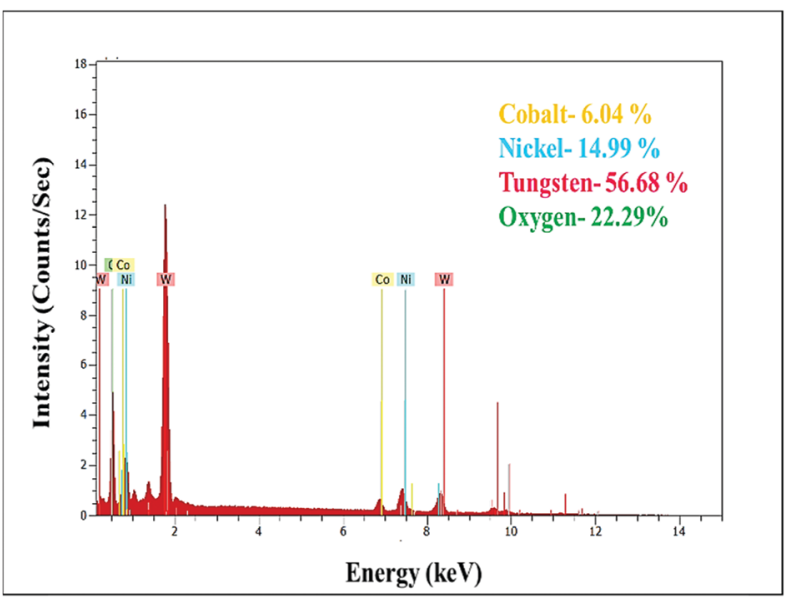

Fig. 4 EDS analysis for (a) $\mathrm{CoWO}_{4}$, and (b) $\mathrm{Ni}-\mathrm{CoWO}_{4}$ nanoparticles.

where the observed binding energies are 40.82, 35.02, and $37.15 \mathrm{eV}$ corresponding to $\mathrm{W} 4 \mathrm{f}_{3 / 2}, \mathrm{~W} 5 \mathrm{p}_{7 / 2}$, and $\mathrm{W} 4 \mathrm{f}_{5 / 2}$, respectively. The high-resolution spectrum of $\mathrm{O} 1 \mathrm{~s}$ shows the corresponding peaks at 529.17, 529.7, and $530.7 \mathrm{eV}$ which signifies the metal oxide bond and the lattice oxygen of the material. The corresponding spectrum is shown in Fig. $5 \mathrm{~d}$.

Optical microscopy (OM) was performed to observe the surface features of the electrodes and the interface of the supercapacitor (Fig. S5(a-j), ESI $\dagger$ ). The carefully prepared cathodes of AC (Fig. S6a, ESI $\dagger$ ) and graphene (Fig. S6b, ESI $\dagger$ ) were studied for surface roughness profiles using an interferometer. These are covered in the ESI, $\dagger$ Section 3.5 (OM) and 3.6 (Interferometer).

\subsection{Electrochemical performance}

To understand the effect of the secondary metal $\left(\mathrm{M}_{2}\right)$ of a bimetallic tungstate on its pseudocapacitance behavior, the electrochemical performance of a bimetallic tungstate $\left(\mathrm{M}_{2} \mathrm{M}_{1} \mathrm{WO}_{x}, \mathrm{M}_{2}=\mathrm{Ni}, \mathrm{M}_{1}=\mathrm{Co}, \mathrm{X}=4\right)$ was compared to that of a metal tungstate $\left(\mathrm{M}_{1} \mathrm{WO}_{x}, \mathrm{M}_{1}=\mathrm{Co}, \mathrm{X}=4\right)$. For this, two cyclic charge-discharge (CCD) experiments (current density = $0.8 \mathrm{~mA} \mathrm{~cm}{ }^{-2}, 2000$ cycles, AC cathode) were performed: one having lignin/NiCoWO ${ }_{4}$ as the composite anode, and the other having lignin/CoWO ${ }_{4}$ as the composite anode. As observed in Fig. 6(a and b), the initial and final areal SPC values for the lignin $/ \mathrm{NiCoWO}_{4}$ pseudocapacitor (1st cycle $\mathrm{SPC}=862.26 \mathrm{mF} \mathrm{cm}^{-2}$, 2000th cycle $\mathrm{SPC}=828.82 \mathrm{mF} \mathrm{cm}^{-2}$ ) are 141 and 1726 times higher, respectively, than those of the lignin/CoWO $\mathrm{Coudo}_{4}$ capacitor (1st cycle SPC $=6.1 \mathrm{mF} \mathrm{cm}{ }^{-2}, 2000$ th cycle $\mathrm{SPC}=$ $0.48 \mathrm{mF} \mathrm{cm}^{-2}$ ). Thus, it is observed that the areal SPC of lignin/ $\mathrm{NiCoWO}_{4}$ is consistently higher than that of the lignin/CoWO pseudocapacitor. Also, the final retention (Fig. 6b) for the lignin/ $\mathrm{NiCoWO}_{4}$ supercapacitor $(96.12 \%)$ is 12.16 times that of the lignin/CoWO4 supercapacitor (7.90\%). Similarly, the SPC of the lignin/ $/ \mathrm{NiWO}_{4}$ supercapacitor for the best ratio $(10: 80: 10)$ is $32.90 \mathrm{mF} \mathrm{cm}^{-2}$ (98.2\% retention, 2000 cycles), that is 26.20 times smaller than that of the lignin/NiCoWO ${ }_{4}$ supercapacitor. Thus, the secondary metal (Ni) of the bimetallic tungstate $\left(\mathrm{NiCoWO}_{4}\right)$ has a tremendous effect in enhancing both the SPC and retention. This enhanced performance can be attributed to the synergistic effect of a highly disordered plate-like morphology (Fig. 3(c and d)) of the bimetallic tungstate NP, obtained through our wet chemical synthesis approach that provides an enhanced surface area for electrochemical reactions; multiple available oxidation states of the transition metals (Ni and $\mathrm{Co}$ ) resulting in a range of redox reactions leading to higher electronic conduction and charge transport; higher access of electrolyte ions and electroactive sites due to inherent defects in the lignin matrix; and a high surface area (S) to volume (V) ratio $(\mathrm{S} / \mathrm{V})$ of the NP due to nanostructuring. These results overcome the limitations of poor cyclability and performance stability of earlier works. ${ }^{41}$

The effects of different constituent mass ratios of the lignin/ $\mathrm{NiCoWO}_{4}$ composite electrode on the electrochemical performance of the pseudocapacitor were studied. This is important to ascertain the contribution from individual constituents (in this case: lignin, $\mathrm{NiCoWO}_{4} \mathrm{NPs}$, and PVDF) to the electrochemical performance which enables the effective design of the pseudocapacitor. Accordingly, three different constituent weight ratios of the composite electrode in the order lignin: $\mathrm{NiCoWO}_{4}$ :PVDF were used and tested in cyclic chargedischarge experiments for 2000 cycles (Fig. 6(c and d)). Of the three samples, sample $80: 10: 10$ has the consistently highest SPC with a maximum value of $862.26 \mathrm{mF} \mathrm{cm}^{-2}$. When the relative percentage of lignin was reduced (sample $75: 15: 10$ ), compared to sample $80: 10: 10$, the SPC dropped by 416 times $\left(1.14 \mathrm{mF} \mathrm{cm}^{-2}\right)$. On the other hand, when the relative percentage of the $\mathrm{NiCoWO}_{4} \mathrm{NP}$ was significantly increased to $75 \%$ by weight (sample $15: 75: 10$ ), compared to sample $75: 15: 10$, the SPC increased by 21 times $\left(23.87 \mathrm{mF} \mathrm{cm}^{-2}\right)$. Thus, the effect of lignin is predominant in affecting the SPC of the pseudocapacitor, and the SPC reduces on reducing the relative weight percent of lignin. This is so because, with a reduction in lignin, the number of active sites is reduced which lowers the charge storage capability of the electro-active material. In comparison, when the relative percentage of the NP is increased, there is an enhancement in the pseudocapacitance due to an increased oxidation-reduction site leading to enhanced charge storage by 

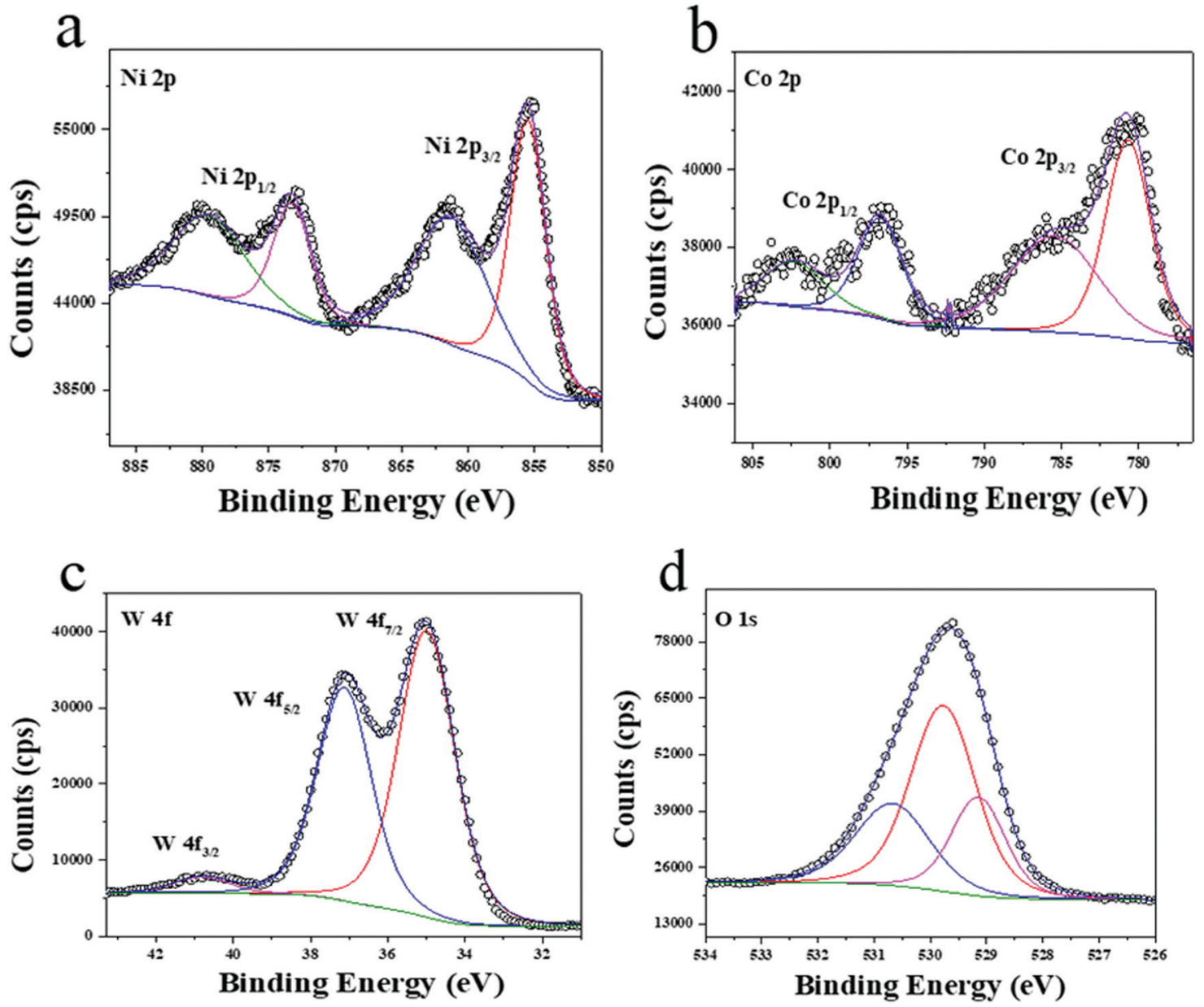

Fig. 5 XPS Spectrum for (a) Ni 2p, (b) Co 2p, (c) W 4f, and (d) O 1s.

the active material. However, this change in SPC due to the NP is less pronounced than due to lignin. The retention plot (Fig. 6d) reveals that with a high percentage of the NP (sample $15: 75: 10)$, capacitance retention is the highest $(100 \%)$. This is on account of the pseudocapacitance property of the NP. The retention of other samples drops since the active sites on lignin get consumed with the progression of cycles. Thus, the mass ratio experiment reveals that while a higher percentage of lignin is required for achieving high SPC, a high relative percentage of the NP is required for attaining high capacitance retention. An optimal value of these constituents can meet the requirement for a high SPC and retention.

The electrochemical performance of a supercapacitor, against varying discharge times (Fig. 6(e and f)), gives an indication of its usability under varied load conditions. The conventional discharge time of a supercapacitor may lie in the range of 1-30 s. ${ }^{54}$ To maximize the energy density of a supercapacitor, it is desired that a supercapacitor can deliver sustained high performance for a longer discharge time. But, at higher discharge times, the cycle life of a supercapacitor is curtailed. This is due to the more rapid consumption of the active sites and a faster generation of decomposition side products that adversely affect its charge storage ability. Thus, the challenge is to obtain a high and sustained electrochemical performance for a longer discharge time. To this effect, the capacitance performance of the lignin/NiCoWO$/ / /$ graphene supercapacitor was evaluated corresponding to the discharge times of 7, 20, and $30 \mathrm{~s}$. The constituent weight ratio (lignin: $\mathrm{NiCoWO}_{4}$ : PVDF) was $75: 15: 10$ in each case. It was observed that the average SPC at $7 \mathrm{~s}$ (Fig. 6(e and f)) was the least, and for $30 \mathrm{~s}$, it was the highest of the three. At the end of 1000 cycles, the SPC for $20 \mathrm{~s}$ $\left(2.6 \mathrm{mF} \mathrm{cm}^{-2}\right)$ was twice that at $30 \mathrm{~s}\left(1.3 \mathrm{mF} \mathrm{cm}^{-2}\right)$. Also, the final retention followed the trend $30 \mathrm{~s}<20 \mathrm{~s}<7 \mathrm{~s}$. However, the difference in the retention between the highest $(7 \mathrm{~s})$ and the lowest (30 s) was only about $11 \%$. Thus, the bimetallic tungstate NP supercapacitor can perform appreciably well even at high discharge times. When the supercapacitor is made to discharge for a longer time, it engages more redox-active sites leading to a larger charge transfer accountable for a higher SPC (as at $30 \mathrm{~s}$ ). However, a higher engagement of the redox-active sites, at longer discharge times, also leads to a faster depletion of newly available redox sites due to reaction products. Thus, at longer discharge times (as at $30 \mathrm{~s}$ ), the supercapacitor has, gradually, a lower ability to store or transfer charge due to a lower availability of new redox-active sites for charge transfer. This leads to poor retention at higher cycles. 
$\mathbf{a}$

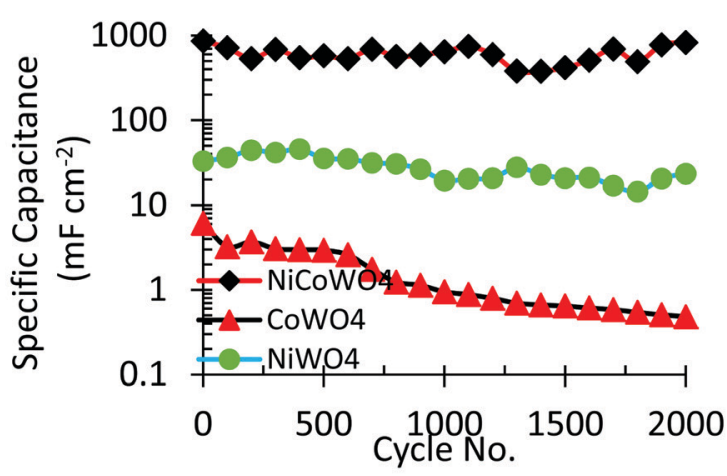

b

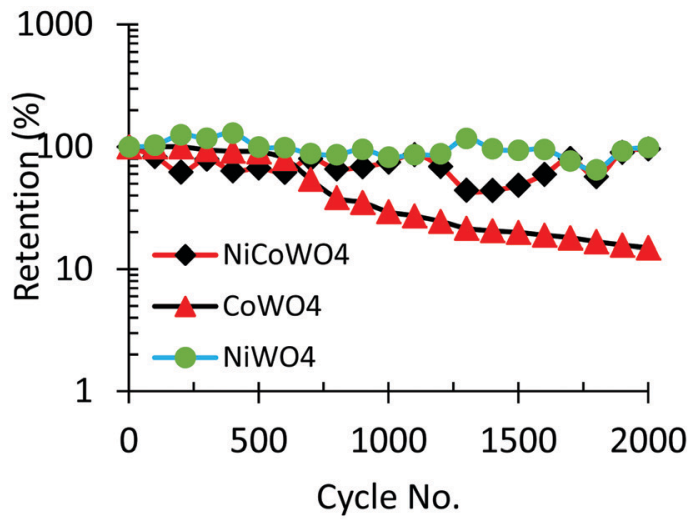

c

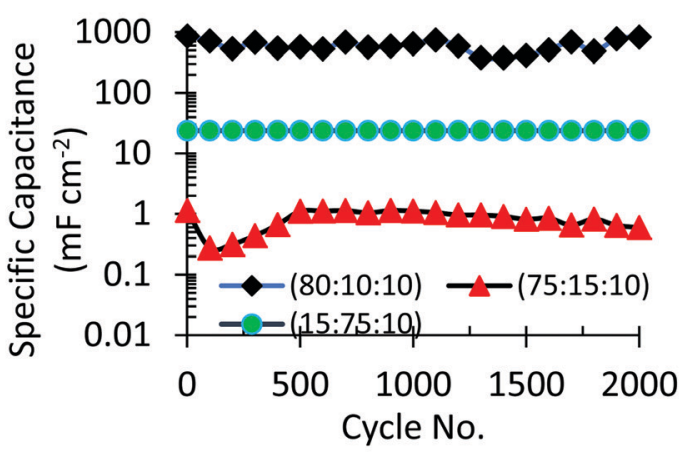

$\mathbf{e}$

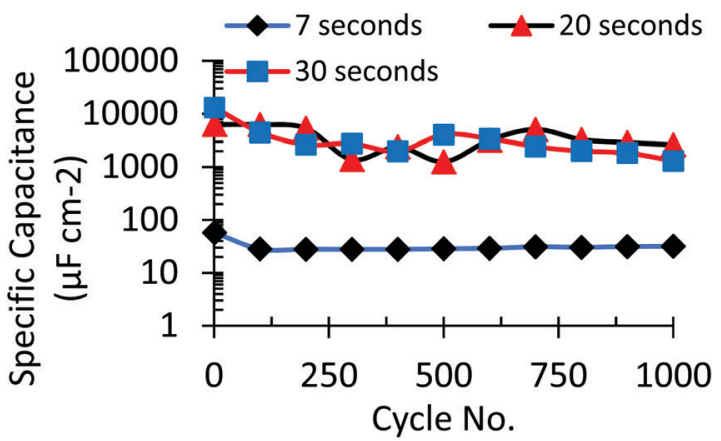

d
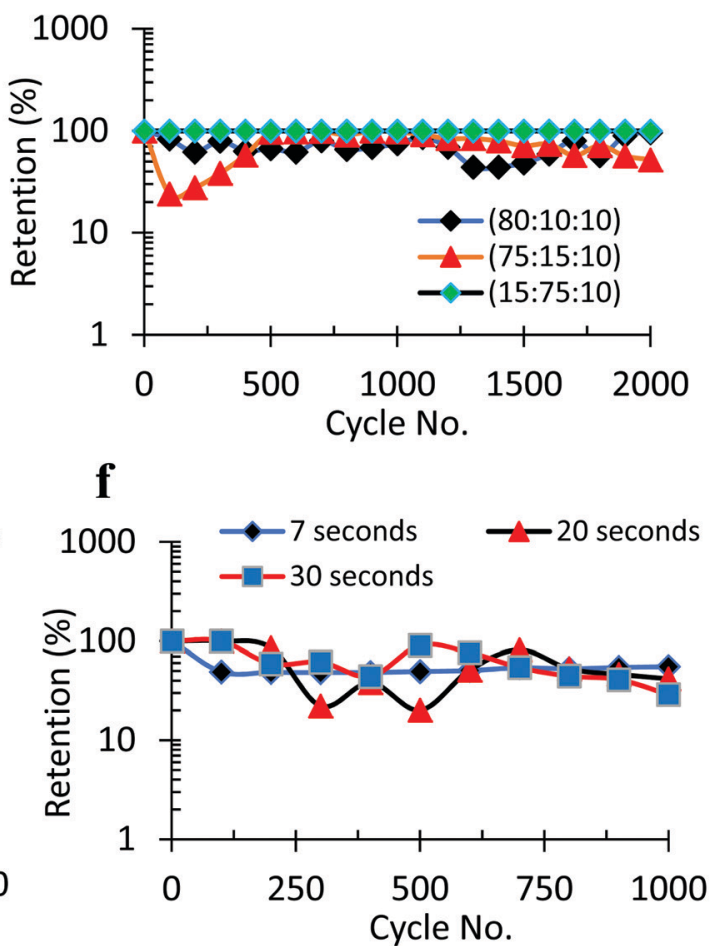

Fig. 6 CCD plots for: the specific capacitance (a) and retention (b) for the lignin/NiCoWO 4 and the lignin/CoWO ${ }_{4}$ supercapacitors with a constituent ratio of $80: 10: 10$ in each and the best ratio $10: 80: 10$ of lignin/NiWO ; specific capacitance (c) and retention (d) under varying mass loadings for the lignin/ $/ \mathrm{NiCoWO}_{4}$ supercapacitor; the specific capacitance (e) and retention (f) under varying discharge times for the lignin/NiCoWO 4 supercapacitor with a constituent ratio of $75: 15: 10$.

The 3D network of carbon chains in lignin molecules plays a big role in impacting its capacitance property. It is intriguing to know how electrochemical performance is affected when these molecular chains are broken into smaller fragments. The carbonization of lignin breaks the long carbon chains in lignin into smaller fragments. It also induces some degree of oxidation. To understand the effect of smaller fragments of the lignin structure and partially oxidized lignin on its capacitance performance, the electrochemical performance of carbonized lignin/ $/ \mathrm{NiCoWO}_{4}$ was assessed using the graphene cathode. It is observed, in Fig. 7a, that the SPC of carbonized lignin/ $\mathrm{NiCoWO}_{4}$ (1st cycle $\mathrm{SPC}=38.09 \mathrm{mF} \mathrm{cm}{ }^{-2}, 2000$ th cycle $\mathrm{SPC}=5.08 \mathrm{mF} \mathrm{cm}^{-2}$ ) is consistently low compared to non-carbonized lignin/ $\mathrm{NiCoWO}_{4}$ (1st cycle SPC $=474.68 \mathrm{mF} \mathrm{cm} \mathrm{cm}^{-2}$, 2000th cycle $\mathrm{SPC}=456.68 \mathrm{mF} \mathrm{cm}^{-2}$ ). Thus, the initial and final values of SPC of the carbonized lignin/ $/ \mathrm{NiCoWO}_{4}$ are only $8 \%$ and $1.2 \%$ as compared to those of non-carbonized lignin/ $/ \mathrm{NiCoWO}_{4}$, respectively. The final retention of carbonized lignin/NiCoWO as shown in Fig. $7 \mathrm{~b}$ is $29 \%$ as compared to that of noncarbonized lignin. Thus, the electrochemical performance of carbonized lignin is inferior to that of non-carbonized lignin. This can be explained by the fact that with the fragmentation of 
$\mathbf{a}$

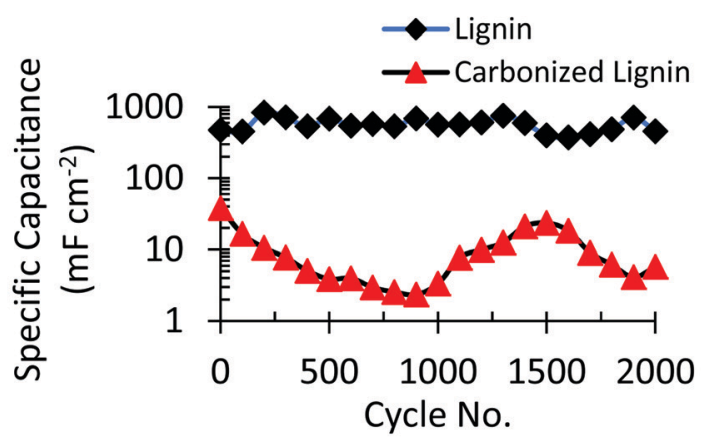

C

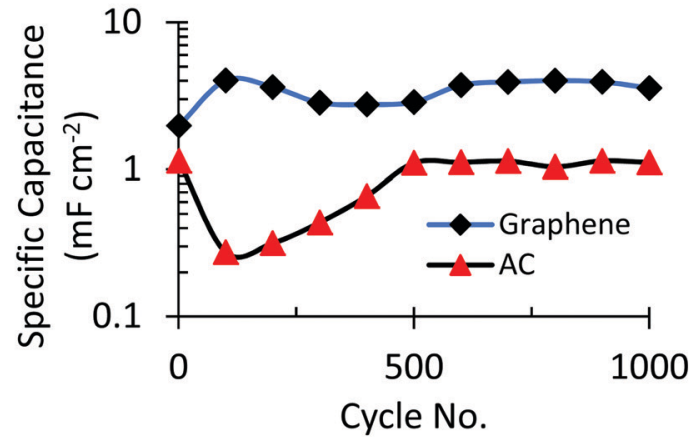

$\mathbf{e}$

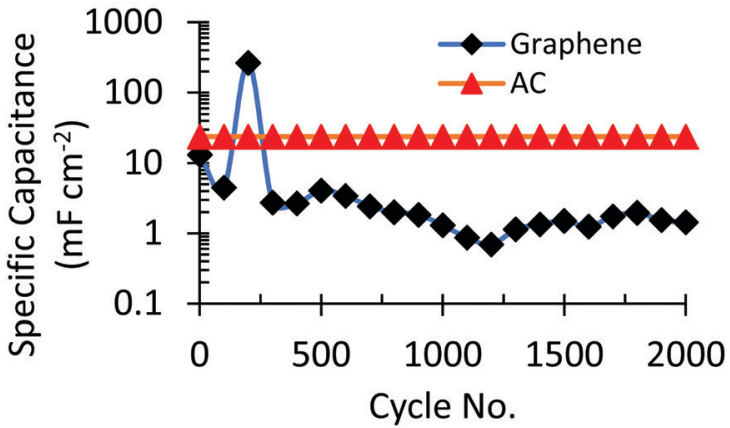

b

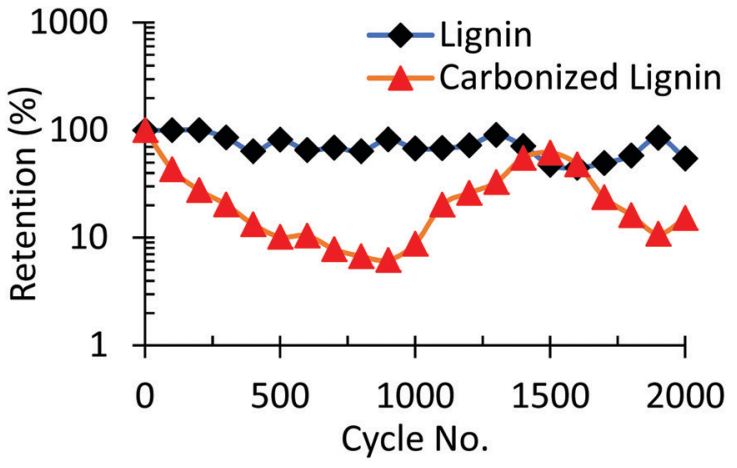

d

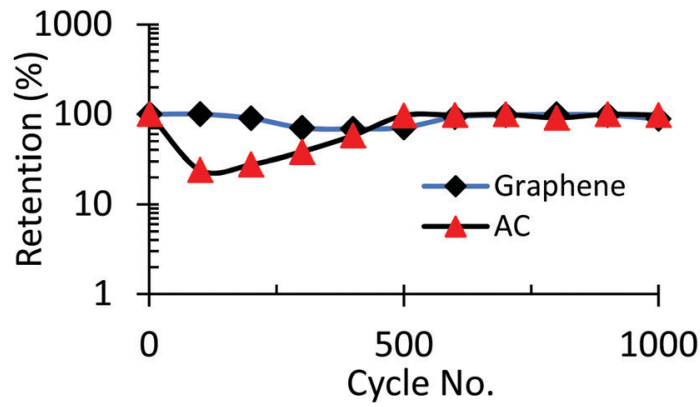

f

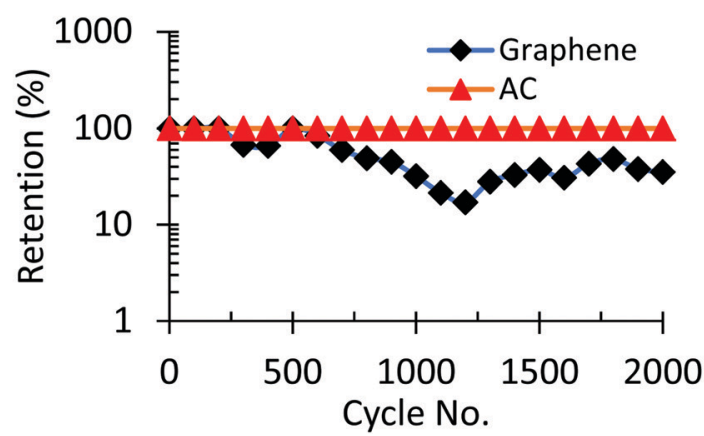

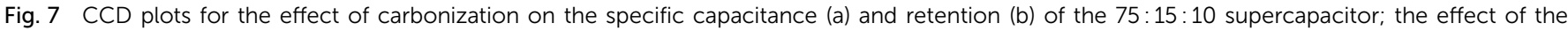

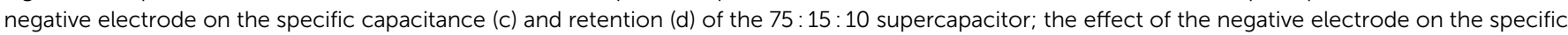
capacitance (e) and retention ( $f$ ) of the 15:75:10 supercapacitor

larger lignin chains into smaller chains in carbonized lignin, there is a considerable increase in disorder in the chain structure and arrangement. This leads to greater impedance to charge transfer resulting in a lesser charge storage ability by the carbonized lignin. Also, carbonized lignin has a greater number of unreactive constituents that do not contribute to any capacitance. This results in a faster fading of capacitance.

The type of cathode material, its conductivity, and surface characteristics play a critical role in a supercapacitor design. The influence of the negative electrode on the electrochemical performance of the bimetallic tungstate supercapacitor was analyzed (Fig. 7(c-f)) and this revealed some interesting trends. Two sets of experiments were performed: in experiment set I (Fig. 7(c and d)), the lignin: $\mathrm{NiCoWO}_{4}$ : PVDF mass ratio was $75: 15: 10$, while in experiment set II (Fig. $7(\mathrm{e}$ and f)), it was
$15: 75: 10$. Thus, in experiment set $I$, the capacitance was electric double-layered capacitor (EDLC) type dominated (due to the higher proportion of lignin) and it was pseudocapacitance dominated in experiment set II (due to a higher proportion of $\left.\mathrm{NiCoWO}_{4}\right) .{ }^{55}$ It was observed that in the EDLC dominated regime (experiment set I), the SPC of the supercapacitor, with graphene as the negative electrode $\left(4.03 \mathrm{mF} \mathrm{cm}^{-2}\right)$, was 3.5 times that with $\mathrm{AC}$ as the negative electrode $\left(1.14 \mathrm{mF} \mathrm{cm}^{-2}\right)$. This can be explained based on a higher value of the dielectric constant of graphene ${ }^{56,57}$ compared to that of $\mathrm{AC}^{58}$ which accounts for a higher SPC (capacitance, $C=\in A / d, A=$ contact surface area, $\epsilon=$ dielectric constant, and $d=$ distance between electrodes $)^{59}$ in an EDLC dominated regime. In contrast, in the pseudocapacitance dominated regime (experiment set II), there is a greater degree of charge transfer and storage due to the pseudocapacitance behavior 


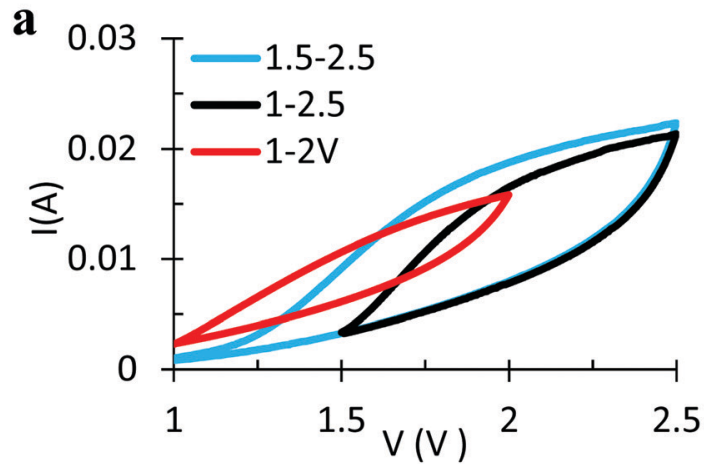

b

c
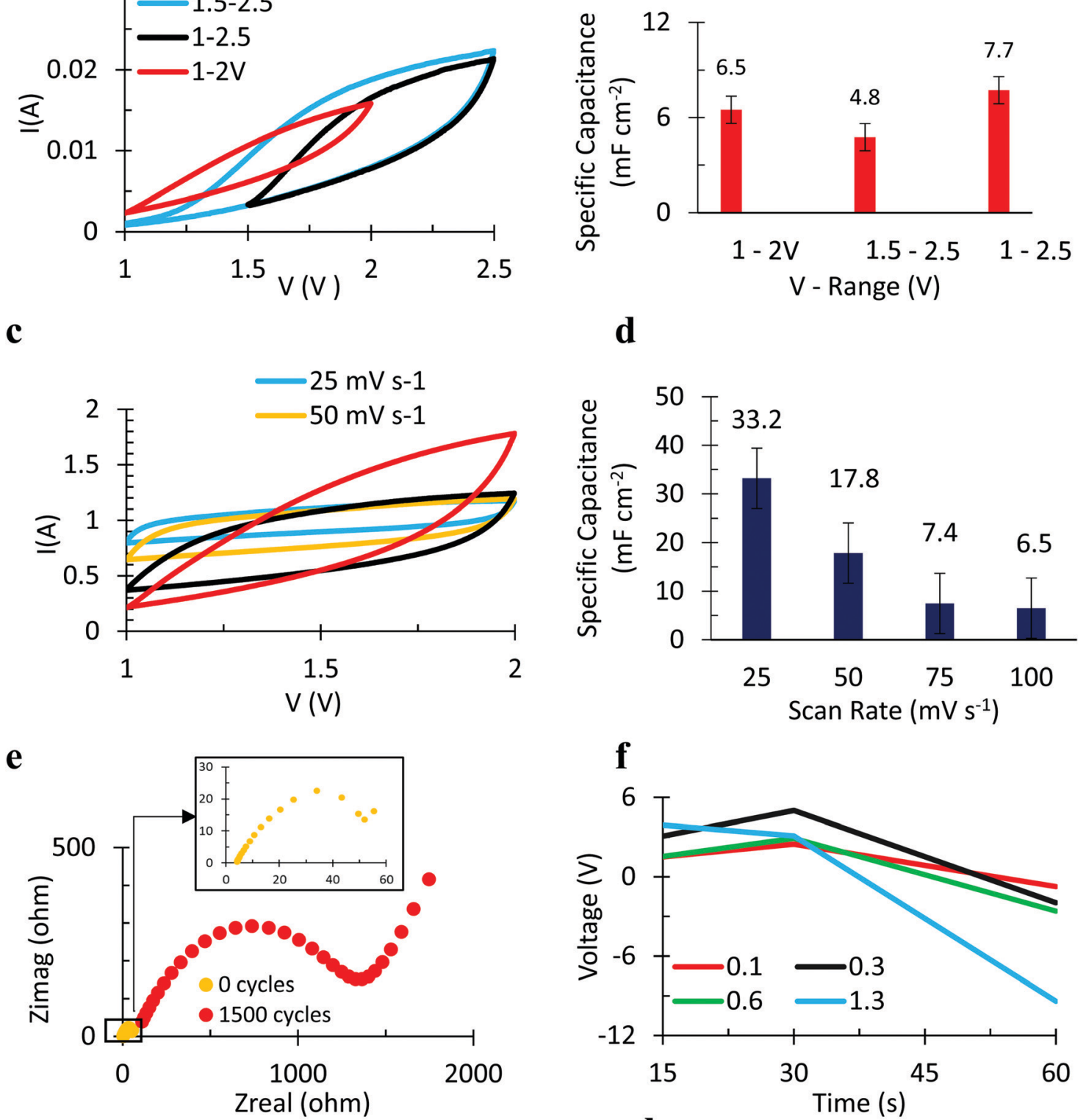

g
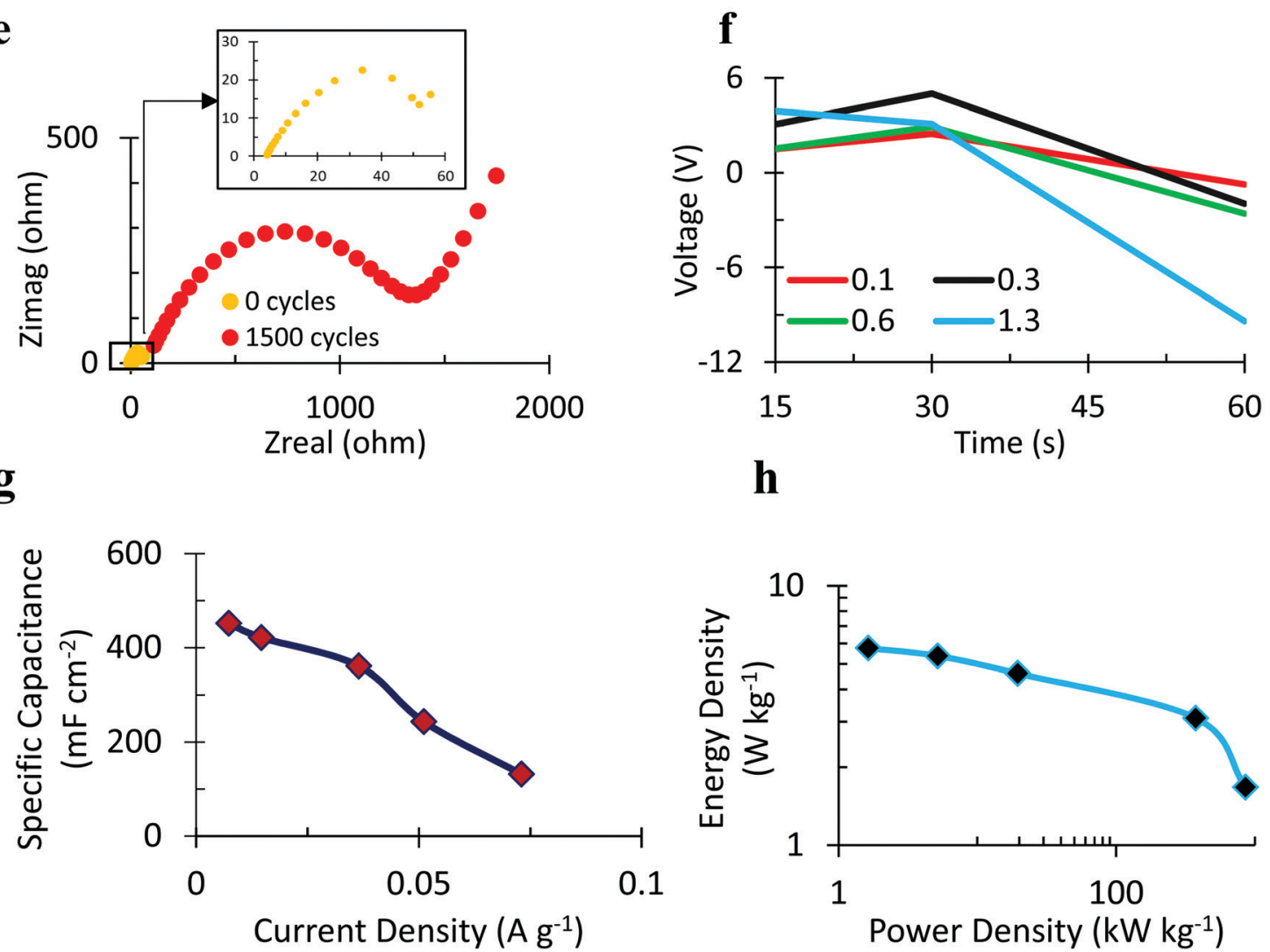

Fig. 8 For the lig-Ni-CoWO windows (b) and scan rates (d); Nyquist plot (e); $V$ vs. $T$ plot (f) at varying current density $\left(\mathrm{A} \mathrm{g}^{-1}\right)$; variation of specific capacitance with current density (g); and the Ragone plot (h). 
of the $\mathrm{NiCoWO}_{4}$ NPS, in addition to the EDLC behavior of lignin. The pseudocapacitance charge transfer heavily depends on the available contact surface area of the electrode-electrolyte at both electrodes of the supercapacitor. Since the AC electrode has a much higher available surface area (A) than the graphene electrode, there is 1.8 times higher charge transfer and storage in the case of the AC electrode $\left(23.88 \mathrm{mF} \mathrm{cm}^{-2}\right.$ ) compared to the graphene electrode (13.13 $\mathrm{mF} \mathrm{cm}^{-2}$ ) in experiment set II. In this case, the higher pseudocapacitance charge transfer contribution in the AC electrode, due to its higher surface area, overpowers the effect of a greater dielectric constant of the graphene electrode. Thus, the electrochemical performance of the bimetallic tungstate supercapacitor was found to be heavily dependent not only on the choice of the negative electrode but also on the type of the dominant regime of charge storage i.e. the EDLC dominated or pseudocapacitance dominated regime. Table S1 (ESI $\dagger$ ) shows a summary of the electrochemical experiments.

To determine the optimal voltage window for the lignin/ $\mathrm{NiCoWO}_{4}$ supercapacitor $(15: 75: 10)$, it was subjected to cyclic voltammetry (CV) as shown in Fig. 8a. The CV curves in the range 1-2 $\mathrm{V}$ and 1.5-2.5 $\mathrm{V}$ are more rectangular compared to the $1-2.5 \mathrm{~V}$ curve, thus, resembling a capacitor behavior more closely. A larger SPC (Fig. 8b) value of $6.5 \mathrm{mF} \mathrm{cm}^{-2}$ (for 1-2 V) compared to $4.8 \mathrm{mF} \mathrm{cm}^{-2}$ (for 1.5-2.5 V) suggests that $1-2 \mathrm{~V}$ is an optimal voltage range of operation. Accordingly, the supercapacitor was cycled at varying scan rates in the $1-2 \mathrm{~V}$ voltage range (Fig. $8 \mathrm{c}$ ) to evaluate the capacitance response (Fig. 8d) under dynamic voltage conditions. SPC followed the order $25>50>75>100 \mathrm{mV} \mathrm{s}^{-1}$ from the greatest $\left(33.2 \mathrm{mF} \mathrm{cm}^{-2}\right)$ to the least $\left(6.5 \mathrm{mF} \mathrm{cm}^{-2}\right)$. This is consistent with the fact that at lower scan rates, there are more instances of reversible charge transfer at the electrode-electrolyte interface that leads to a higher SPC. To account for the loss of capacitance at higher cycles, Electro Impedance Spectroscopy (EIS) was performed and Nyquist plots are obtained as shown in Fig. 8e for the $80: 10: 10$ sample. The total impedance of the supercapacitor at the beginning (0th cycle) is about $50 \mathrm{Ohm}$ while it is about 1.5 kilo-Ohms after 1500 cycles as seen by the intersection of the semicircle on the $X$-axis. A higher impedance to charge transfer at a higher cycle number accounts for diminishing charge storage ability. The slope of the $V-t$ plot in Fig. 8f reveals that at a higher applied discharge current density, the decay of voltage is steeper which is a typical characteristic of a supercapacitor. The negative slope of the SPC $v s$. current density plot in Fig. $8 \mathrm{~g}$ reveals that at a higher discharge current density, the SPC decreases. This too is a typical supercapacitor behavior. The Ragone plot (Fig. 8h) shows very high values of energy and power densities due to the synergistic effect of bimetallic tungstate NPs encapsulated in lignin. Table S2 (ESI $\dagger$ ) shows the comparison of the electrochemical performance of the supercapacitor with the literature reports.

\section{Conclusions}

In this research, we studied the role of the secondary metal $\left(\mathrm{M}_{2}\right)$ in the pseudocapacitance of bimetallic tungstate type compounds $\left(\mathrm{M}_{2} \mathrm{M}_{1} \mathrm{WO}_{4}, \mathrm{M}_{2}=\mathrm{Ni}, \mathrm{M}_{1}=\mathrm{Co}\right)$. It was discovered that the bimetallic tungstate $\left(\mathrm{NiCoWO}_{4}\right)$ functionalized lignin supercapacitor displayed a high SPC value of $862.26 \mathrm{mF} \mathrm{cm}^{-2}$ that was 141 times higher than that of the monometallic tungstate $\mathrm{CoWO}_{4}\left(6.1 \mathrm{mF} \mathrm{cm}{ }^{-2}\right)$ functionalized lignin supercapacitor. The secondary metal $\mathbf{M}_{2}$ in the bimetallic tungstate $\left(\mathrm{M}_{2} \mathrm{M}_{1} \mathrm{WO}_{4}\right.$, $\mathbf{M}_{2}=\mathrm{Ni}, \mathbf{M}_{1}=\mathrm{Co}$ ) significantly enhances the pseudocapacitance due to a higher available oxidation state leading to high electronic conduction. The lignin/NiCoWO ${ }_{4}$ supercapacitor also shows a very high-power density of $854.76 \mathrm{~kW} \mathrm{~kg}^{-1}$ and a maximum energy density of $5.75 \mathrm{~W} \mathrm{~h} \mathrm{~kg}{ }^{-1}$ due to the synergistic effect of the bimetallic tungstate NP encapsulated in lignin. With a higher proportion of the bimetallic tungstate NP in the composite electrode, the capacitance retention increased. For an optimal mass ratio of lignin : $\mathrm{NiCoWO}_{4}: \mathrm{PVDF}$ (15: $75: 10)$, the retention was $100 \%$ even after 2000 cycles. The study on supercapacitor discharge time showed a higher SPC at higher discharge times while higher retention at lower discharge times. Thus, the rate of consumption of electroactive sites of the pseudocapacitance nanomaterial $\left(\mathrm{NiCoWO}_{4}\right)$ was linear with discharge time. Carbonization breaks down the lignin molecular structure which creates a high impedance to charge transport and diminished electrochemical performance. The capacitive performance of the bimetallic tungstate supercapacitor was found to heavily depend on the choice of the negative electrode's dielectric permittivity and surface area, and on the type of the dominant regime of charge storage i.e. the EDLC dominated or pseudocapacitance dominated regime. Thus, this work provides a new knowledge base for the effective use and design of bimetallic tungstate-based nano-bioelectronic devices which will promote green technology.

\section{Conflicts of interest}

There are no conflicts to declare.

\section{Acknowledgements}

The authors would also like to thank Yan Chen for help with interferometer images. We also thank Weston Stewart and Raj Likhari for their contribution to experimental data collection, and Peter Renner for help with lignin carbonization.

\section{References}

1 Z. Bi, Q. Kong, Y. Cao, G. Sun, F. Su, X. Wei, X. Li, A. Ahmad, L. Xie and C.-M. Chen, J. Mater. Chem. A, 2019, 7, 16028-16045.

2 Y. Gong, D. Li, C. Luo, Q. Fu and C. Pan, Green Chem., 2017, 19, 4132-4140.

3 J. Wang, P. Nie, B. Ding, S. Dong, X. Hao, H. Dou and X. Zhang, J. Mater. Chem. A, 2017, 5, 2411-2428.

4 J. Deng, M. Li and Y. Wang, Green Chem., 2016, 18, 4824-4854.

5 Y. Liu, Y. Yang, Z. Peng, Z. Liu, Z. Chen, L. Shang, S. Lu and T. Zhang, Nano Energy, 2019, 65, 104023. 
6 Y. Liu, X. Yong, Z. Liu, Z. Chen, Z. Kang and S. Lu, Adv. Sustainable Syst., 2019, 3, 1800161.

7 D. Sheberla, J. C. Bachman, J. S. Elias, C.-J. Sun, Y. ShaoHorn and M. Dincă, Nat. Mater., 2017, 16, 220-224.

8 E. Pomerantseva, F. Bonaccorso, X. Feng, Y. Cui and Y. Gogotsi, Science, 2019, 366, eaan8285.

9 Y. Yue and H. Liang, Adv. Energy Mater., 2017, 7, 1602545.

10 Y. Yue and H. Liang, J. Power Sources, 2015, 284, 435-445.

11 S. Jha, Y. Chen, B. Zhang, A. Elwany, D. Parkinson and H. Liang, J. Appl. Electrochem., 2020, 50, 231-244.

12 S. Jha, V. Ponce and J. M. Seminario, J. Mol. Model., 2018, 24, 290.

13 T. M. Gür, Energy Environ. Sci., 2018, 11, 2696-2767.

14 H. Jin, J. Li, Y. Yuan, J. Wang, J. Lu and S. Wang, Adv. Energy Mater., 2018, 8, 1801007.

15 S. Zhou, L. Zhou, Y. Zhang, J. Sun, J. Wen and Y. Yuan, J. Mater. Chem. A, 2019, 7, 4217-4229.

16 H. Lu and X. S. Zhao, Sustain. Energy Fuels, 2017, 1, 1265-1281.

17 G. Zhang, X. Xiao, B. Li, P. Gu, H. Xue and H. Pang, J. Mater. Chem. A, 2017, 5, 8155-8186.

18 J. M. Gonçalves, M. I. da Silva, H. E. Toma, L. Angnes, P. R. Martins and K. Araki, J. Mater. Chem. A, 2020, 8, 10534-10570.

19 K. J. Griffith, K. M. Wiaderek, G. Cibin, L. E. Marbella and C. P. Grey, Nature, 2018, 559, 556-563.

20 T. Ling, P. Da, X. Zheng, B. Ge, Z. Hu, M. Wu, X.-W. Du, W.-B. $\mathrm{Hu}, \mathrm{M}$. Jaroniec and S.-Z. Qiao, Science, 2018, 4, eaau6261.

21 Y. Huang, C. Yan, X. Shi, W. Zhi, Z. Li, Y. Yan, M. Zhang and G. Cao, Nano Energy, 2018, 48, 430-440.

22 A. M. Priya, R. K. Selvan, B. Senthilkumar, M. Satheeshkumar and C. Sanjeeviraja, Ceram. Int., 2011, 37, 2485-2488.

23 A. S. Rajpurohit, N. S. Punde, C. R. Rawool and A. K. Srivastava, Chem. Eng., 2019, 371, 679-692.

24 M. Denk, D. Kuhness, M. Wagner, S. Surnev, F. R. Negreiros, L. Sementa, G. Barcaro, I. Vobornik, A. Fortunelli and F. P. Netzer, ACS Nano, 2014, 8, 3947-3954.

25 R. Lacomba-Perales, J. Ruiz-Fuertes, D. Errandonea, D. Martínez-García and A. Segura, EPL, 2008, 83, 37002.

26 S. M. Hosseinpour-Mashkani and A. Sobhani-Nasab, J. Mater. Sci.: Mater. Electron., 2016, 27, 7548-7553.

27 M. Feng, D. An, H. Zhang, G. Ma, C. Zhang and Z. Ma, Int. J. Chem. Stud., 2017, 5, 1954-1960.

28 D. W. Kim, I.-S. Cho, S. S. Shin, S. Lee, T. H. Noh, D. H. Kim, H. S. Jung and K. S. Hong, J. Solid State Chem., 2011, 184, 2103-2107.

29 K. Hoang, M. Oh and Y. Choi, RSC Adv., 2018, 8, 4191-4196. 30 K. Hoang, Phys. Rev. Mater., 2017, 1, 024603.

31 T. Mathew, N. Batra and S. K. Arora, J. Mater. Sci., 1992, 27, 4003-4008.

32 T. Montini, V. Gombac, A. Hameed, L. Felisari, G. Adami and P. Fornasiero, Chem. Phys. Lett., 2010, 498, 113-119.

33 S. H. Yoon, D.-W. Kim, S.-Y. Cho and K. S. Hong, J. Eur. Ceram. Soc., 2006, 26, 2051-2054.

34 V. Nagirnyi, M. Kirm, A. Kotlov, A. Lushchik and L. Jönsson, J. Lumin., 2003, 102, 597-603.
35 R. Bharati, R. Singh and B. Wanklyn, J. Phys. Chem. Solids, 1982, 43, 641-644.

36 R. Bharati, R. Singh and B. Wanklyn, J. Mater. Sci., 1980, 15, 1293-1296.

37 Y. Liu, X. Li, Q. Zhang, W. Li, Y. Xie, H. Liu, L. Shang, Z. Liu, Z. Chen, L. Gu, Z. Tang, T. Zhang and S. Lu, Angew. Chem., Int. Ed., 2020, 59, 1718-1726.

38 Y. Wang, C. Shen, L. Niu, Z. Sun, F. Ruan, M. Xu, S. Shan, C. Li, X. Liu and Y. J. M. C. Gong, Physics, 2016, 182, 394-401.

39 W. H. Low, P. S. Khiew, S. S. Lim, C. W. Siong and E. R. J. J. O. A. Ezeigwe, Compounds, 2019, 775, 1324-1356.

40 W. Li, Z. Wei, B. Wang, Y. Liu, H. Song, Z. Tang, B. Yang and S. Lu, Materials Chemistry Frontiers, 2020, 4, 277-284.

41 W. H. Low, P. S. Khiew, S. S. Lim, C. W. Siong and E. R. Ezeigwe, J. Alloys Compd., 2019, 775, 1324-1356.

42 S. M. Pourmortazavi, M. Rahimi-Nasrabadi, M. KhalilianShalamzari, H. R. Ghaeni and S. S. Hajimirsadeghi, Polym. Mater., 2014, 24, 333-339.

43 S. M. M. Zawawi, R. Yahya, A. Hassan, H. E. Mahmud and M. N. Daud, Chem. Cent. J., 2013, 7, 80.

44 A. Phuruangrat, T. Thongtem and S. Thongtem, J. Ceram. Soc. Jpn., 2008, 116, 605-609.

45 P. Parhi, T. Karthik and V. J. J. o. A. Manivannan, Compounds, 2008, 465, 380-386.

46 X. Cui, S. H. Yu, L. Li, L. Biao, H. Li, M. Mo and X. M. Liu, Chem. - Eur. J., 2004, 10, 218-223.

47 R. Talebi, J. Mater. Sci. Mater., 2016, 27, 3565-3569.

48 P. A. Shinde and S. C. Jun, ChemSusChem, 2020, 13, 11-38.

49 U. Nithiyanantham, S. R. Ede, T. Kesavan, P. Ragupathy, M. D. Mukadam, S. M. Yusuf and S. Kundu, RSC Adv., 2014, 4, 38169-38181.

50 U. Nithiyanantham, S. R. Ede, S. Anantharaj and S. Kundu, Crystal Growth Design, 2015, 15, 673-686.

51 S. Jha, S. Mehta, Y. Chen, L. Ma, P. Renner, D. Y. Parkinson and H. Liang, ACS Sustain. Chem. Eng., 2020, 8, 498-511.

52 S. Jha, S. Mehta, Y. Chen, P. Renner, S. S. Sankar, D. Parkinson, S. Kundu and H. Liang, J. Mater. Chem. C, 2020, 8, 3418-3430.

53 S. Jha, S. Mehta, Y. Chen, R. Likhari, W. Stewart, D. Parkinson and H. Liang, Energy Storage, 2020, e184.

54 A. González, E. Goikolea, J. A. Barrena and R. Mysyk, Renewable Sustainable Energy Rev., 2016, 58, 1189-1206.

55 Y. Shao, M. F. El-Kady, J. Sun, Y. Li, Q. Zhang, M. Zhu, H. Wang, B. Dunn and R. B. Kaner, Chem. Rev., 2018, 118, 9233-9280.

56 R. Bessler, U. Duerig and E. Koren, Nano. Adv., 2019, 1, 1702-1706.

57 S. Bellucci, A. Maffucci, S. Maksimenko, F. Micciulla, M. D. Migliore, A. Paddubskaya, D. Pinchera and F. Schettino, Materials, 2018, 11, 2519.

58 F. Shkal, S. Lopez, D. Slocombe and A. Porch, J. Comput. Commun., 2018, 06, 112-123.

59 J. Phillips, Materials, 2018, 11, 1519. 